Short Communication

\title{
EFFECTIVENESS OF JACOBSON'S PROGRESSIVE MUSCLE RELAXATION (JPM R) TECHNIQUE ON SOCIAL ANXIETY AM ONG HIGH SCHOOL ADOLESCENTS IN A SELECTED SCHOOL OF UDUPI DISTRICT, KARNATAKA STATE
}

\author{
Febu Elizabeth Joy ${ }^{1}$, Tessy Treesa Jose ${ }^{2} \&$ Asha K. Nayak ${ }^{3}$ \\ ${ }^{1}$ Lecturer, Amrita College of Nursing AIM S, Kochi, ${ }^{2}$ Professor \& HOD, ${ }^{3}$ Assistant Professor, \\ Department of Psychiatric Nursing, M anipal College of Nursing, M anipal University, M anipal, INDIA \\ Correspondence: \\ Tessy Treesa Jose \\ Professor \& HOD, Psychiatric Nursing, Manipal College of Nursing Manipal, Manipal University, Manipal, INDIA. \\ Mobile : +91 9844152459 E-mail : tessy.j@manipal.edu
}

Abstract:

Problem: Epidemiologic studies show that social anxiety is among the most prevalent of all mental disorders and very less attention has been given to this area.

Methods: The purpose of this exploratory study was to identify the adolescents with social anxiety and teach the JPM R technique to those who would score high on social anxiety scale. The data were collected from 193 high school adolescents using Demographic Proforma, Social Anxiety Scale for Adolescent and Tool to Assess the Associated Factors of Social Anxiety. The JPM R technique was administered to the adolescents with moderate to severe social anxiety.

Findings: The study found that $52(27 \%)$ adolescents were having moderate social anxiety and there was significant association $\left(\chi^{2}=15.297, p<0.05\right)$ between age of the adolescents and social anxiety. The significant related factors of social anxiety were parental strictness, parental conflict, teacher's strictness, peer rejection, troubled with appearance and being treated differently from siblings by parents. The Jacobson's Progressive Muscle Relaxation Technique was found to be effective ( $t=10.646, d f=39, p=0.001)$ in reducing the social anxiety.

Conclusion : Social anxiety is common among adolescents and many modifiable factors related to parents and teachers are associated with it. Appropriate interventions in an early time may help them to reduce it.

Keywords : Social anxiety, Social phobia, Jacobson's Progressive M uscle Relaxation

\section{Introduction :}

Adolescence is a transitional stage of physical and mental human development that occurs between childhood and adulthood. This transition involves biological, social and psychological changes which are shaped by the social environment in which they live. The social environment provides the opportunity, barriers, role models and support for individual's Access this article online Quick Response Code

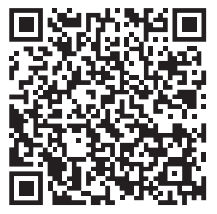
development and health. Systems within the social environment include family, peers, schools, community and the large society and these all contribute to an adolescent's development and health. The future of our country depends on the mental health and strength of our young people. (Wilson \& Hockenberry, 2007)

Period of adolescence can be stressful for children and parents. Children are dealing with the challenges of going through puberty, meeting changing expectations and coping with new feelings. Most of the children meet these challenges successfully and grow into healthy adults while others have a harder time coping with all these problems. (Aggarwal, Prabhu \& Anand, 2007)

Mental, emotional and behavioral disorders among children, youth and young adults create an enormous burden for their families and nation. They threaten the future health and well being of young people. A review of 
three longitudinal studies concluded that close to

percent of young people had at least one psychiatric disorder by the time they are 16 years. Anxiety disorders are among the most common mental, emotional, and behavioral problems to occur during childhood and adolescence. About 13 of every 100 adolescents between the age of 9 to 17 years experience some kind of anxiety disorder (Sanderson, Tilse, Nicholson, Oldenburg \& Graves, 2007).

An exploratory study was conducted to find out the frequency, demographic and phenomenological characteristics of social anxiety disorder (SAD), family related factors, academic impairments and comorbidity of depression among adolescents in Ahmadabad. The result showed that 54 (12.8\%) adolescents had SAD (M ehtalia and Vankar, 2004). In recent years, it has been increasingly acknowledged that anxiety disorders are highly prevalent in the general adult population. Recent worldwide estimates for the 1-year lifetime prevalence of any anxiety disorders is $10.6 \%$ (Somers, Goldner, Waraich \& Hsu, 2006).

Physical activity is an important means of reducing stress levels and preventing some of its damaging effects on the body. Exercise uses up the adrenaline and other hormones which the body produces under stress and relaxes the muscles. It will help to strengthen the heart and improve blood circulation (Townsend, 2005). An exploratory study was conducted to find out the effectiveness of meditation and progressive relaxation as treatments for symptoms of stress. Subjects were recruited from advertisements in local newspapers and received five sessions of training. All subjects self-monitored, stress symptoms throughout the study and had their behavior rated weekly by a spouse/roommate. The progressive relaxation and meditation treatments resulted in a significant reduction of stress symptomatology over time (Woolfolk, Lehrer, M cCann \& Rooney, 1982). Research suggests that physical activity can lead to a change in body chemistry which can affect the way people feel as well as their physical condition.

Different types of relaxation techniques can also help to raise self-esteem and reduce anxiety and depression. It is necessary to identify the students with social anxiety and teach Jacobson's Progressive Muscle Relaxation technique which will help them to overcome the anxiety and improve the self-esteem.

\section{Objectives:}

Objectives of the study were to:

1. identify the students with social anxiety

2. find out the association between social anxiety and selected demographic varaibles such as age ,gender,type o family and birth order of the students

3. find out the relationship between social anxiety and its assiciated factors

4. determine the effectiveness of Jacobson's progressive muscle relaxation on social anxiety in terms of reduction in post test anxiety score

\section{Materials and Methods: \\ Subjects/Participants}

Prior to conducting the study administrative permission was taken from the Head M istress of the school. Consent was taken from the parents and participants. The study population comprised of eighth and ninth standard adolescent students who were between the age group of 12-14 years of St. Mary's English Medium High School, Udupi, Karnataka State, India.The sample size for the study was 193 and a non probability purposive sampling was adopted to select the samples.

\section{Study design}

Evaluative approach with one group pre test posttest design wasused for the study.

\section{Measures}

The data were collected using demographic proforma, Social anxiety scale for adolescents and Scale to assess the associated factors of social anxiety.

The demographic proforma was designed to collect the background information of the subjects. It consists six items including roll number, class in which the student studying, age, gender, type of the family and birth order. The social anxiety scale was constructed by the researcher 
based on the Social Anxiety Scale for Adolescents (La Greca and Lopez, 1998), Social Phobia Inventory Scale (Connor et al., 2000) and Leibwotiz Social Anxiety Scale for Adolescents (Leibwotiz, MR, 1992). The purpose of the scale was to identify the students with social anxiety. The five point likert type scale consists of 22 items which covered the areas on fear of negative evaluation, authority context, social events and stranger context. The total score ranges from 0-88. The third tool had 27 items on parental strictness, parental support, parental conflict, discrimination among siblings, peer influence and teacher strictness. A total score was

not given as each item is directly related to the social anxiety. The tools were given to experts for content validity and necessary modifications were made according to the expert's suggestions. The reliability coefficients for social anxiety scale for adolescents and tool to assess the associated factors of social anxiety were determined by Cronbach's alpha and the reliability coefficients were 0.82 and 0.84 respectively.

\section{Procedure:}

The researcher met the participants in the school and the Headmistress introduced the researcher to them and purpose of the study was explained. The questionnaires were distributed to all the $8^{\text {th }}$ and $9^{\text {th }}$ standard students who were present on the day of data collection. There were 193 students present on the day of data collection. The students with moderate to severe social anxiety were identified from the data on social anxiety. There were 52 students with moderate and five students with severe social anxiety.

The Jacobson's Progressive Muscle Relaxation Technique was initiated after one week as the students were busy with their academic schedule. On first day only 51 students were present and they were divided into three groups (fifteen, eighteen and eighteen). The researcher arranged a convenient place for conducting the JPM R technique and the morning time was chosen to practice the technique. The instruction regarding the performance of the relaxation was given to the subjects and it was demonstrated to them which took around 45 minutes. Subjects practiced the Jacobson's Progressive Relaxation under the supervision of the researcher for ten days and only 40 students attended all the ten sessions. The post test was given on the $10^{\text {th }}$ day immediately after the JPM R.

\section{Data analysis:}

Descriptive statistics was used to identify the sample characteristics. Categorical data was compared using Chi square test. Paired $\underline{t}$ test was used to find out the significance difference between the mean pretest and mean post test scores. Relationship between social anxiety and associated factors of social anxiety were analyzed by Spearman rank correlation.

\section{Results:}

\section{Description of the sample characteristics}

Out of 193 subjects, majority (59.1\%) of the children were in the age group of $14-15$ years. The boys constituted $66.8 \%$ of the sample and the girls were only $33.2 \%$. With regard to the birth order there was equal distribution to first and second born i.e. 83(43\%), 11(5.7\%) were third born, $2(1 \%)$ were fourth born and 14 (7.3\%) were only child in the family. Data on type of family show that 173 (89.6\%) were from nuclear family, 17 (8.8\%) were from joint and only $3(1.6 \%)$ were from extended family.

Fig. 1 Pie diagram showing the frequency and percentage of students with social anxiety

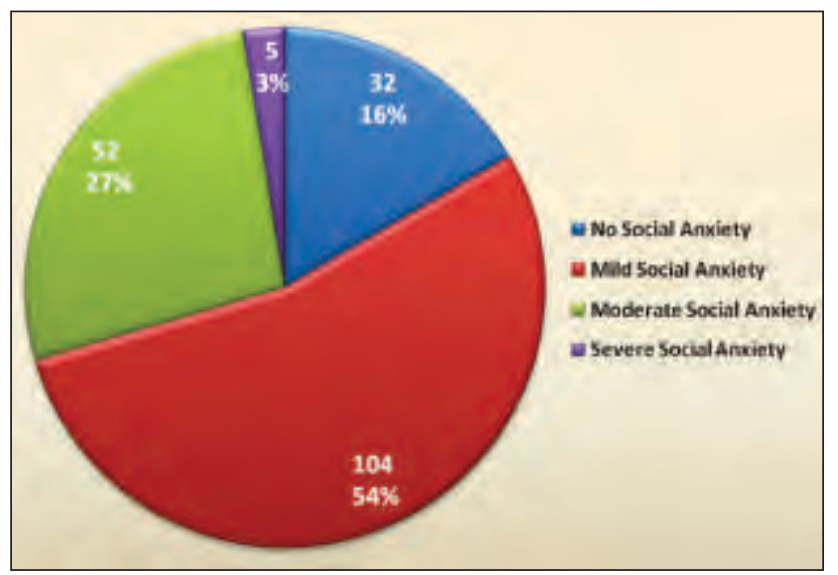


Table1. Chi square value computed between social anxiety and selected demographic variables $(n=193)$ Variables No Mild Moderate Severe $\chi^{2}$ df $p$

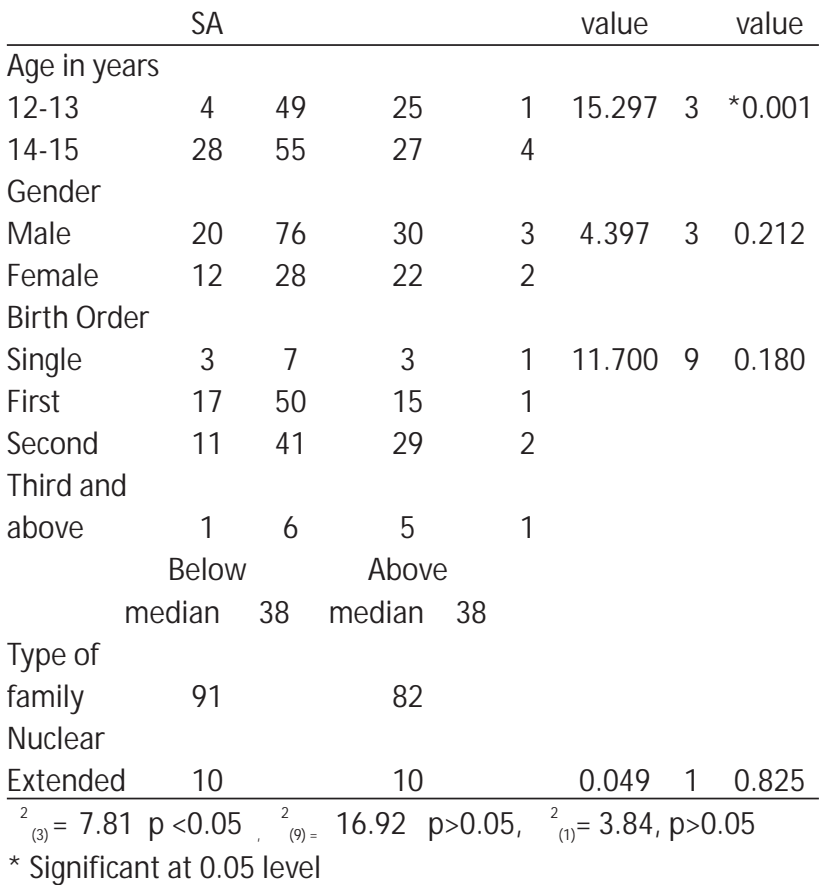

Table 2. Correlation coefficient computed between social anxiety and associated factors

$(n=193)$

\begin{tabular}{|c|c|c|c|}
\hline Factors & & r value & $p$ value \\
\hline Parental strictness & & 0.507 & $0.001^{*}$ \\
\hline Parental conflicts & & 0.175 & $0.015^{*}$ \\
\hline Peer rejection & Social anxiety & 0.497 & $0.001 *$ \\
\hline Teachers strictness & & 0.199 & $0.005 *$ \\
\hline $\begin{array}{l}\text { Troubled with appearance } \\
\text { ? Discrimination among }\end{array}$ & & 0.456 & $0.001 *$ \\
\hline siblings & & 0.176 & $0.018 *$ \\
\hline
\end{tabular}

* Significant at 0.05 level $\mathrm{df}_{(192)}=0.195$

$? \mathrm{n}=179$. Only 179 students had siblings

\section{Description of students with social anxiety}

The social anxiety was assessed using Social Anxiety Scale for adolescents. M ajority of the adolescents i.e. 104 (54\%) experienced mild social anxiety. Moderate social anxiety was experienced by $52(27 \%)$ adolescents and 5(3\%) adolescents experienced severe social anxiety Thirty two (16\%) children did not experience any social anxiety (Fig.1).

\section{Association between social anxiety and selected demographic variables}

The chi square computed to find the association between social anxiety and selected variables revealed that there is significant association between age and social anxiety $\left(\chi^{2}=15.297, d f=3, p=0.001\right)$. Thus it can be interpreted that social anxiety is dependent on age (Table 1). But there was no significant association between the gender, type of family, birth order and social anxiety. (Table 1).

\section{Relationship between social anxiety \& associated factors}

Significant but weak positive correlation was observed between social anxiety and with parental strictness $(r=0.507, p=0.001)$, parental conflict $(r=0.175, p=0.015)$, peer rejection $(r=0.497, p=0.001)$ and teachers strictness $(r=0.199, p=0.005)$ and were troubled with their appearance $(r=0.456, p=0.001)$. Data also revealed that these adolescent children were treated differently as compared to their brothers and sisters by parents $(r=0.176$, $p=0.018$ ). (Table 2 ).

\section{Effectiveness of JPM R on social anxiety}

The mean difference between pre test and post test scores (14.45) was significant at 0.05 level $(t=10.646, d f=39$, $p=0.001$ ) indicating that JPM R therapy was effective in reducing the social anxiety.

\section{Other relevantfinding}

As the age was a continuous variable the Spearman rho was also computed between age of the adolescents and social anxiety $\quad(r=0.411, p<0.01)$ and found a significant positive correlation. Hence it can be interpreted that as the age increases social anxiety also increases.

\section{Discussion :}

The goal of the study was to identify the students with social anxiety and evaluate the effectiveness of Jacobson's Progressive Muscle Relaxation in reducing the social anxiety. The findings of the present study showed that out of the 193 samples, majority of the children i.e.

104 (54\%) experienced mild social anxiety. M oderate social anxiety was experienced by $52(27 \%)$ children, $5(3 \%)$ children experienced severe social anxiety. Thirty two (16\%) children

did not experience any social anxiety. These findings 
supports the exploratory study conducted in Ahmadabad to find out the frequency, demographic and phenomenological characteristics of social anxiety disorder (SAD), family related factors, academic impairments and comorbidity of depression among adolescents. Four twenty one adolescents in a high school were screened for SAD and depression and associated factors with academic impairments using Social anxiety

Inventory Scale, Brief Patient Health Questionnaire and questionnaire on factors associated with social anxiety disorder. The result showed that 54(12.8\%) adolescents had SAD (M ehtalia and Vankar, 2004).

Present study revealed a significant positive correlation between social anxiety and associated factors such as parental strictness, parental conflicts, teacher's strictness, peer rejection, troubled with appearance and discrimination among siblings. These findings support the proposition of parental acceptance-rejection theory (Rohner et al, 2007). Adolescent's perception of a warm and accepting quality in the relationship with their parents is remarkably important to maintain their healthy psychological adjustment because their security and other emotional and psychological states are dependent on it (Rohner et al, 2007).The findings of the present study also support the study conducted by M ehtalia \& Vankar (2004) in Ahmadabad. The result showed that 54(12.8\%) adolescents had social anxiety disorder. The most common manifestations were avoiding giving speeches, performing or giving talk in front of audience, being centre of attention and speaking up at a meeting. Most of these manifestations of social anxiety disorder were equally found among boys and girls. Social anxiety disorder was also associated with difficulty in coping with studies, concern about weight, having fewer friends, lack of intimacy with parents and being treated differently form siblings.

In the present study it was observed that the mean post test anxiety score was significantly lower than the mean post test score which was significant at 0.05 level. This finding supports an evaluative study conducted to determine the effects of single session of meditation and progressive muscle relaxation on stress reduction. The progressive muscle relaxation group had the greatest decline in somatic anxiety (Wachelka \& Katz,1999).

Few limitations noted for the present study were the study was limited to only one school and non probability sampling technique was used to select the samples. So the study can

not be generalized to a larger population. Self construction of the tools such as social anxiety scale for adolescents, tool to assess the associated factors of social anxiety and non establishment of construct validity may contribute to errors in the findings.

\section{Conclusion :}

Despite limitations, results from this study suggest that Jacobson's Progressive Muscle Relaxation Technique is effective in reducing the social anxiety. Replication of this study, using a more powerful design and large sample size is a needed next step. Nursing, in $21^{\text {st }}$ century, looks forward for more independent roles in health care system. These kind of interventional therapies have manifold effects on human life and health. This study finding has contributed to strengthen this aspiration of nursing profession to reach a greater height of independence on education and service.

\section{References:}

1. Agarwal S, Prabhu HR \& Anand A. Stressful life events among adolescents: The development of a new measure. Indian Journal of Psychiatry. 2007; 49(2): 96-101

2. M ehtalia K\& Vankar GKSocial anxiety in adolescents. Indian Journal of Psychiatry.2004: 46(3): 221-7.

3. Rohner R., Khaleque, A, Cournoyer DE Parental acceptance, rejection, theory, methods, evidence and implications. Retrieved February 2, 2007, from http://vm.uconn.edu/

4. Sanderson K, Tilse E, Nicholson J, Oldenburg B.Graves N. Which presenteeism measures are more sensitive to depression and anxiety? Journal of Affective Disorder.2007; 101 (3),:65-74.

5. Somers JM, Goldner EM, Waraich P, Hsu L. Prevalence and incidence studies of anxiety disorders: a systematic review of the literature. Canadian Journal of Psychiatry.2006;51(2):100-13. Available from URL: http://www.ncbi.nlm.nih.gov/pubmed/

6. Townsend MC. Psychiatric mental health nursing -Concept of Care.Philadelphia: F.A. Davis Publishers; 2005

7. Wilson, Hockenberry. Wong's nursing care of infant and Children. Philadelphia: M osby Publications;2007.

8. Woolfolk RL, Lehrer PM , M cCann BS, Rooney AJ. Effects of progressive relaxation and meditation on cognitive and somatic manifestations of daily stress. Behavioral Research Therapy.1982 ;20(5): 461-7.Available from URL:http://www.ncbi.nlm.nih.gov/pubmed/6758758 